\begin{tabular}{|c|l|}
\hline Title & $\begin{array}{l}\text { Rediscovery after thirty years since the last capture of the critically endangered Okinawa spiny rat Tokudaia muenninki } \\
\text { in the northern part of Okinawa Island }\end{array}$ \\
\hline Author(s) & $\begin{array}{l}\text { Yamada, Fumio; Kawauchi, Norihiro; Nakata, Katsushi; A be, Shintaro; Kotaka, Nobuhiko; Takashima, A tsushi; } \\
\text { Murata, Chie; Kuroiwa, A sato }\end{array}$ \\
\hline Citation & $\begin{array}{l}\text { Mammal Study, 35(4), 243.255 } \\
\text { https://doi.org/10.3106/041.035.0404 }\end{array}$ \\
\hline Issue Date & 2010-12 \\
\hline Doc URL & http://hdl.handle.net/2115/47531 \\
\hline Type & article \\
\hline File Information & MS35-4_243-255.pdf \\
\hline
\end{tabular}

Instructions for use 


\title{
Rediscovery after thirty years since the last capture of the critically endangered Okinawa spiny rat Tokudaia muenninki in the northern part of Okinawa Island
}

\author{
Fumio Yamada ${ }^{1, *}$, Norihiro Kawauchi ${ }^{2, * *}$, Katsushi Nakata ${ }^{3}$, Shintaro Abe ${ }^{4}$, \\ Nobuhiko Kotaka ${ }^{5}$, Atsushi Takashima ${ }^{6}$, Chie Murata $^{7}$ and Asato Kuroiwa ${ }^{7,8}$ \\ ${ }^{1}$ Forestry and Forest Products Research Institute, Tsukuba, Ibaraki 305-8687, Japan \\ ${ }^{2}$ Island Ecology Institute, Ginowan, Okinawa 901-2206, Japan \\ ${ }^{3}$ Yambaru Wildlife Conservation Center, Ministry of the Environment, Kunigami, Okinawa 905-1413, Japan \\ ${ }^{4}$ Naha Nature Conservation Office, Ministry of the Environment, Naha, Okinawa 900-0027, Japan \\ ${ }^{5}$ Kyushu Research Center, Forestry and Forest Products Research Institute, Kumamoto, Kumamoto 860-0862, Japan \\ ${ }^{6}$ Yona Field, Subtropical Field Science Center, Faculty of Agriculture, University of the Ryukyus, Kunigami, Okinawa \\ 905-1427, Japan \\ ${ }^{7}$ Graduate School of Life Science, Hokkaido University, Sapporo, Hokkaido 060-0810, Japan \\ ${ }^{8}$ Laboratory of Animal Cytogenetics, Faculty of Science, Hokkaido University, Sapporo, Hokkaido 060-0810, Japan
}

\begin{abstract}
The Okinawa spiny rat, Tokudaia muenninki, is a critically endangered species endemic to the northern part of Okinawa Island and may be extinct in the wild as there have been no recent sightings of the animal in its natural habitat. We initiated the present search to determine whether the spiny rat still exists in the northern part of Okinawa Island. Sensor cameras and traps were distributed across areas in which past studies had identified the location of occurrence of spiny rats. From a total of 1,276 camera-nights and 2,096 trap-nights from 2007 to 2009, we captured 24 spiny rats; however, we were only successful in identifying spiny rats in the northernmost of the areas sampled, with no indications of the spiny rat in the more southerly areas. The area in which the spiny rats were still present was estimated to be only $1-3 \mathrm{~km}^{2}$ and is comprised of forest dominated by Castanopsis sieboldii, Lithocarpus edulis, Distylium racemosum and Schima wallichii. The trees range in age from about 30 to more than 100 years old, and have an average height of $12 \mathrm{~m}$ (range $7 \mathrm{~m}-16 \mathrm{~m}$ ). Our rediscovery of the spiny rat in 2008 comes after an interval of 30 years since the previous trapping study in 1978 and seven years since indirect survey evidence from analysis of feral cat feces 2001. Measures for conservation of the location of the spiny rats are urgently required.
\end{abstract}

Key words: body measurements, conservation, critically endangered species, distribution, extinction.

Habitat loss, the impact of invasive species and overhunting are major factors leading to extinction of threatened mammalian species (Hilton-Taylor 2000). In many cases, species extinction has gone unrecognized due to the lack of continuous monitoring and investigation. Four mammalian species, Pteropus loochoensis, Pipistrellus sturdeei, Canis lupus hattai and Canis lupus hodophilax, have become extinct in Japan and 15 others are critically endangered (Ministry of the Environment 2002). One of these critically endangered species, the Okinawa spiny rat Tokudaia muenninki (Rodentia,
Muridae), has not been sighted recently in its natural habitat, raising concerns that it might be extinct in the wild (Kaneko 2005).

The genus Tokudaia exists as a relic on the Ryukyu archipelago, the most southwestern region of Japan, and has three species: T. muenninki (Johnson 1946) on Okinawa Island, T. tokunoshimensis (Endo and Tsuchiya 2006) on Tokunoshima Island and T. osimensis (Abe 1933) on Amami-ohshima Island (Endo et al. 2008; Iwasa 2009). The genus is characterized by its possession of an extremely unusual chromosomal constitution

*To whom correspondence should be addressed. E-mail: fumio@ffpri.affrc.go.jp

**Present address: Yachiyo Engineering Co., Ltd, Naha, Okinawa 900-0015, Japan 
for mammals. This is exemplified by the different chromosomal constitutions of three species: T. muenninki has $2 n=44$ with an $\mathrm{XX} / \mathrm{XY}$ sex chromosome system; T. tokunoshimensis has $2 n=45$ with an $\mathrm{X} 0 / \mathrm{X} 0$ sex chromosome system; and, $T$. osimensis has $2 n=25$ with an X0/X0 sex chromosome system (Tsuchiya et al. 1989; Sutou et al. 2001; Arakawa et al. 2002; Kobayashi et al. 2007, 2008; Nakamura et al. 2007; Kuroiwa et al. 2010; Murata et al. 2010). The three species show differences in mtDNA and rDNA sequences, and their cranial characteristics and external measurements also vary (Suzuki et al. 1999, 2000; Kaneko 2001; Endo et al. 2008). The genus Tokudaia is thought to be related to Margaretamys of Sulawesi or to the fossil Parapodemus (Kaneko 2005).

Tokudaia muenninki is classified as a critically endangered species, while T. osimensis (named T. tokunoshimensis before 2006) is designated as endangered in the Japanese Red list (Ministry of the Environment 2002). In 1972, the genus Tokudaia was designated a Natural Monument of Japan by the Japanese Government.

The islands in the Ryukyu archipelago show unique biodiversity, including, for example, the Ryukyu longfurred rat Diplothrix legata that is endemic to only three islands, Okinawa, Tokunoshima and Amami-ohshima, and the Amami rabbit Pentalagus furnessi that is only endemic to two islands, Tokunoshima and Amamiohshima. Pentalagus which is thought to have existed on Okinawa during the Pleistocene as fossil Pentalagus were recently discovered there and dated to $1.5-1.7$ MYA (Ozawa 2009). These unique species including Tokudaia evolved in the absence of terrestrial predatory mammals on these islands.

The present study was initiated to determine whether T. muenninki was still present in the northern part of Okinawa Island. To this end, we set up sensor cameras and traps to confirm the occurrence of the spiny rats; we also collected tissue samples from trapped animals for cytogenetic comparisons with the other two Tokudaia species (Kobayashi et al. 2007, 2008; Nakamura et al. 2007; Kuroiwa et al. 2010; Murata et al. 2010). In this report, we describe the rediscovery of the species and the habitat conditions in the area in which it was still extant. We also obtained body measurement data and determined the reproductive condition of the trapped individuals in order to increase the record on this critically endangered species and to aid its conservation. There is little descriptive information available from live specimens of this species, with the exception of studies in
1978 (Mitsui 1979) and in 1945 (Johnson 1946). We also discuss possible reasons for the reduction in the distribution of this species and consider potential steps to aid its conservation.

\section{Study areas and methods}

\section{Study areas}

The study areas were located in the northern part of Okinawa Island, in which past studies had identified locations in which spiny rats were present (Fig. 1). Three search areas (Areas I, II and III) were investigated in the northern part of Okinawa Island in this study and these are distinguished by geographical location and by the dates on which they were studied. The dates shown for Areas I, II and III, and the ellipse shaded with oblique lines and on the ellipse shaded with black indicate habitats investigated by this and past studies: 2008/2009 in Area I refers to this study; 2001 in Area II was studied by Jogahara et al. (2003); 1997 in Area III was studied by Ohshima et al. (1997); 1978 in Area III was studied

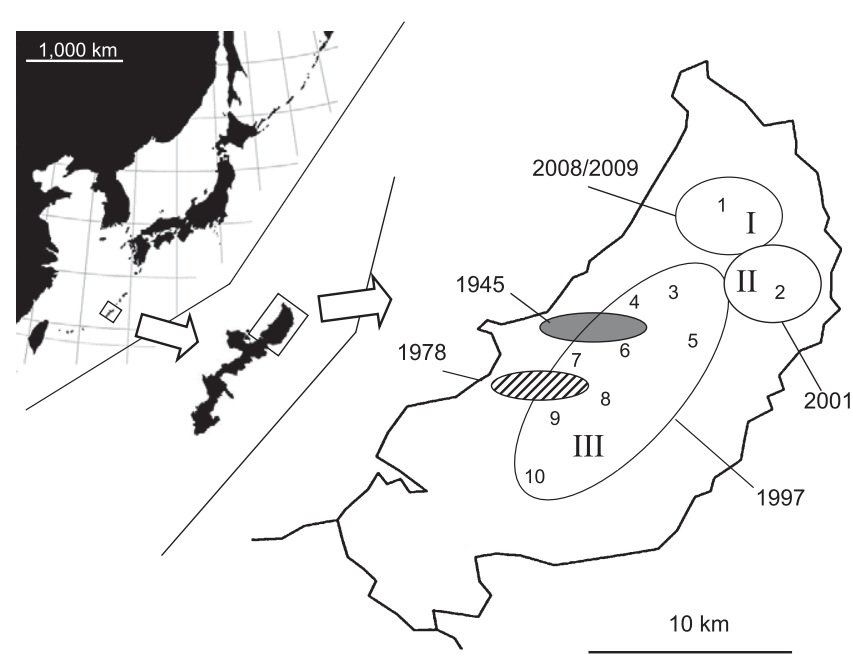

Fig. 1. Geographical locations of Areas I, II and III in the northern part of Okinawa Island that were searched for the presence of Tokudaia muenninki from 2007 to 2009. For conservation reasons, we show only an approximate outline of the location of the main habitat (Area I). Details on these areas are given in Tables 1, 2 and 6. The date shown on Areas I, II and III, and on the ellipse shaded with oblique lines and on the ellipse shaded with black indicate when these habitats were investigated: 2008/2009 in Area I indicates the present study; 2001 in Area II is the study of Jogahara et al. (2003); 1997 in Area III is the study of Ohshima et al. (1997); 1978 in Area III is the study of Mitsui (1979); 1945 in Area III is the study of Johnson (1946). The main landmarks of these areas are as follows: 1, Mt. Nishime; 2, Mt. Ibu; 3, Mt. Fuenchiji; 4, Yona River; 5, Aha River; 6, Mt. Yonaha; 7, Iji at the Ohkkuni Forest Road; 8, Mt. Iyu; 9, Hiji at the Ohkuni Forest Road; 10, Mt. Tamatsuji. 
by Mitsui (1979); and 1945 in Area III was studied by Johnson (1946) (Fig. 1). The main landmarks of these areas are: 1, Mt. Nishime; 2, Mt. Ibu; 3, Mt. Fuenchiji; 4, Yona River; 5, Aha River; 6, Mt. Yonaha; 7, Iji at the Ohkkuni Forest Road; 8, Mt. Iyu, 9, Hiji at the Ohkuni Forest Road; 10, Mt. Tamatsuji.

The sampled areas consist of broadleaved forests and have valleys that range in elevation from 200 to $300 \mathrm{~m}$ above sea level. Annual temperatures varied between 5.2 and $33.9^{\circ} \mathrm{C}$, and annual precipitation ranged from 1,978 to 3,603 mm during the ten-year period 1999-2008 at the Oku Observation Point $\left(26^{\circ} 50.0 \mathrm{~N}, 128^{\circ} 16.3 \mathrm{E}\right.$, and $232 \mathrm{~m}$ above sea level) in the village of Kunigami. The study areas included 22 forest sites dominated by Castanopsis sieboldii.

\section{Sensor camera census}

Between 40 and 60 sets of cameras with the infrared sensors FieldNote I and II (Marif Co., Japan) were used to search for spiny rats from January 2008 to March 2009; in total, nine sites were selected in the study areas (Table 1). At each site monitored by cameras, we set baits consisting of Castanopsis sieboldii acorns and peanuts to entice animals into the monitored areas.

\section{Trapping}

Trapping surveys were carried out in March and December 2007, February and March 2008, and February 2009 because of the expectation of high efficiency of capture in the early spring and winter seasons. Between 30 and 140 cage traps, with dimensions of $15 \times 10 \times 15$ $\mathrm{cm}$, were used at 14 sites in the forests. The sites of sensor camera census and trapping surveys did not overlap completely as we did not carry out a sensor camera census in 2007 and we did not carry out trapping surveys if no spiny rats were found in a preliminary camera census. Each trap was covered by a plastic bag to waterproof against rainfall. The traps were baited with several acorns of Castanopsis sieboldii, cuts of sweet potato Ipomoea batatas, slices of fish sausage, dried small sardines, and peanuts. The traps were set during the daytime and checked thereafter each morning. Spiny rats captured in this study were transported to the Yambaru Wildlife Conservation Center of the Ministry of the Environment in the village of Kunigami where the following measurements were made on unanaesthetized animals held in a mesh bag: body weight (BW), head and body length (HBL), tail length (T), hind foot length excluding the claws (HFL), ear length (EL), and the length between the anus and the genital organ (Jackson distance). A small piece was cut from the tip of the tail of each spiny rat and used for cytogenetic comparisons with other species. After completion of these procedures, all the spiny rats were released at their capture sites. The Agency for Cultural Affairs (Permission No. 4-2051) and the Ministry of the Environment of Japan (Permission Nos. 080207001, 090120002 and 090601001) permitted capture of a maximum of 5 to 10 individuals per year.

\section{Age classification and sex determination}

We determined the age and sex of each trapped individual to examine the relationship between these factors and the measured external morphological characters (see above). For age classification, females with a body weight greater than $130 \mathrm{~g}$ and males heavier than $120 \mathrm{~g}$ were classified as adults. This weight classification system is based on the results of a previous study in 1978 that examined the characteristics of sexually mature individuals (Mitsui 1979). Mature females were identified by the presence of an open vaginal orifice and prominent nipples, while the mature males had descended testes. The presence of undeveloped spines on the body was used to identify juveniles. Animals with a lower body weight than an adult but which had fully grown spines were classified as sub-adult.

As externally visible secondary sexual characteristics are only present in adults during the reproductive season and are not visible in juveniles, we used the Jackson distance (see above) to determine the sex of captured individuals. We confirmed this classification by PCR analysis for the $S R Y$ gene and by karyotype analysis (Murata et al., 2010).

\section{Vegetation in the capture site}

We determined the vegetation profile at each site at which spiny rats were captured. One or three plots (each $10 \mathrm{~m}^{2}$ ) were assessed at each site. Three tree layers and the understory layer, including herbs and ferns, were classified vertically on each plot. A measuring pole was used to determine the heights of trees in the upper tree layer of each plot. The relative plant coverage of each tree layer over the ground was assessed subjectively by eye. Slope inclinations and directions were measured using a clinometer. We assessed a total of nine plots on May 29, 2009 for this study.

The history of forest management at each site where spiny rats were captured was determined based on the 
Table 1. Number of sensor cameras at each site and the number of cameras which successfully photographed Tokudaia muenninki individuals in the nothern part of Okinawa Island from 2008 to 2009

\begin{tabular}{|c|c|c|c|c|c|c|}
\hline Area & Site & Place name* & Period of camera set & $\begin{array}{l}\text { Total number of } \\
\text { camera-nights }\end{array}$ & $\begin{array}{c}\text { Number of spiny rats } \\
\text { photographed }\end{array}$ & $\begin{array}{l}\text { Ratio of spiny rats } \\
\text { photographed per } 100 \\
\text { camera-nights }\end{array}$ \\
\hline I & N6 & Mt. Nishime (1) & $2008.02 .12-05.10$ & 399 & 9 & 2.25 \\
\hline I & N11 & Mt. Nishime (1) & $2009.01 .07-25$ & 139 & 137 & 98.35 \\
\hline II & $\mathrm{Ib} 1$ & Mt. Ibu (2) & 2008.01.27-02.09 & 114 & 0 & 0.00 \\
\hline III & $\mathrm{Y} 2$ & Mt. Yonaha (6) & $2008.01 .13-27$ & 176 & 0 & 0.00 \\
\hline III & $\mathrm{F} 1$ & Mt. Fuenchiji (3) & 2008.02.10-14 & 9 & 0 & 0.00 \\
\hline III & $\mathrm{O} 1$ & $\begin{array}{l}\text { Hiji at the Ohkuni } \\
\text { Forest Road (9) }\end{array}$ & $2008.02 .10-11$ & 5 & 0 & 0.00 \\
\hline III & $\mathrm{O} 2$ & $\begin{array}{l}\text { Iji at the Ohkuni } \\
\text { Forest Road (7) }\end{array}$ & $2008.04 .26-05.16$ & 22 & 0 & 0.00 \\
\hline III & YR1 & Yona River (4) & 2008.12.27-2009.01.05 & 91 & 0 & 0.00 \\
\hline III & YR1 & Yona River (4) & $2009.02 .27-03.12$ & 322 & 0 & 0.00 \\
\hline Mean & & & & & & 11.44 \\
\hline Total & & & & 1,276 & 146 & \\
\hline
\end{tabular}

* The numbers in parentheses indicate site positions in Fig. 1.

report of Watanabe (2008), who analyzed aerial photos taken in 1970, 1977, 1993 and 2003.

\section{Statistical analyses}

ANOVA tests with the Holm method were used to analyze differences in external measurements between the females and males collected in this study and between the adult individuals recorded here and those described in a previous studies in 1978 (Mitsui 1979) and in 1945 (Johnson 1946) ; differences were considered significant at $P<0.05$.

\section{Results}

\section{Locations of successful captures}

The sensor cameras provided of total of 1,276 cameranights (Table 1). Spiny rats were recognized only in Area I (Fig. 1): the ratio of photo captures of spiny rats was highest at Site N11 in Area I with 98.35 photos /100 camera-nights; the ratio of photo captures was lower (2.25/100 camera-nights) at Site N6 in Area I (Table 1). The sensor cameras did not identify spiny rats in Areas II and III (Table 1).

In the trapping survey, a total of 2,096 trap-nights was used (Table 2). Spiny rats were only captured in Area I. The capture ratio at Site N11 in Area I was highest at 24.14 spiny rats per 100 trap-nights (Table 2). Significant ratios of trapping success were also obtained for Sites N7 (7.81), N6 (3.94), and N9 (2.22) in Area I, and low ratios in three sites (N8, N3 and N4) (Table 2).
However, even in Area I, no spiny rats were captured at Sites N1, N2, N5, or N10.

The estimated sizes of the trapping sites were $0.06 \mathrm{~km}^{2}$ for Site N3 and N4, $0.12 \mathrm{~km}^{2}$ for Sites N6, N7, N8 and N9, and $0.005 \mathrm{~km}^{2}$ for Site N11. Therefore, the main area where spiny rats occurred, estimated as the polygon from the most external points of each captured site, was $1-3 \mathrm{~km}^{2}$ in Area I (Fig. 1). For reasons of conservation, we have presented only a rough outline of this region in Figure 1.

No spiny rats were recorded in Areas II and III using photo census or trapping methods.

\section{Vegetation profile of the capture site}

The topography of the main site in which spiny rats were found included small ridges, slopes and small mountain valleys. Overall, the topographies of the sampling Areas did not vary significantly, and showed a mean slope of $17^{\circ}$ (range 5-25 $)$ with variable direction (Table 3). The average tree height in main site was $12 \mathrm{~m}$ (range $7 \mathrm{~m}-16 \mathrm{~m}$ ), and the trees ranged in age from about 30 years to more than 100 years old. The relative plant coverage over the ground in the upper tree layer was approximately $71 \%$ (40-90\%), approximately $71 \%$ (30$90 \%)$ in the middle tree layer, approximately $66 \%(30$ $100 \%$ ) in the lower tree layer, and approximately $22 \%$ $(5-40 \%)$ in the understory layer (Table 3$)$. The capture sites of the spiny rats were in forest dominated by Castanopsis sieboldii, Lithocarpus edulis, Distylium racemosum and Schima wallichii in the upper tree layer, 
Table 2. Number of traps and number of Tokudaia muenninki individuals captured in the nothern part of Okinawa Island from 2007 to 2009

\begin{tabular}{|c|c|c|c|c|c|c|c|}
\hline Area & Site & Place name* & Period of traps set & $\begin{array}{c}\text { Total number of } \\
\text { nights }\end{array}$ & $\begin{array}{l}\text { Total number of } \\
\text { trap-nights }\end{array}$ & $\begin{array}{c}\text { Number of } \\
\text { spiny rats captured }\end{array}$ & $\begin{array}{c}\text { Capture ratio of } \\
\text { spiny rats per } 100 \\
\text { trap-nights }\end{array}$ \\
\hline I & N1 & Mt. Nishime (1) & $2007.03 .06-09,20-22$ & 7 & 59 & 0 & 0.00 \\
\hline I & N2 & Mt. Nishime (1) & 2007.12.24-29 & 6 & 67 & 0 & 0.00 \\
\hline I & $\mathrm{N} 3$ & Mt. Nishime (1) & 2008.02.28-03.05 & 6 & 326 & 4 & 1.23 \\
\hline I & N4 & Mt. Nishime (1) & $2008.03 .03-07$ & 5 & 150 & 1 & 0.67 \\
\hline I & N5 & Mt. Nishime (1) & 2008.03.09-10 & 2 & 18 & 0 & 0.00 \\
\hline I & N6 & Mt. Nishime (1) & $2009.02 .14-17$ & 4 & 127 & 5 & 3.94 \\
\hline I & N7 & Mt. Nishime (1) & 2009.02.14-17 & 4 & 64 & 5 & 7.81 \\
\hline I & $\mathrm{N} 8$ & Mt. Nishime (1) & $2009.02 .14-17$ & 4 & 76 & 1 & 1.32 \\
\hline I & N9 & Mt. Nishime (1) & $2009.02 .15-17$ & 3 & 45 & 1 & 2.22 \\
\hline I & N10 & Mt. Nishime (1) & $2009.02 .15-17$ & 3 & 36 & 0 & 0.00 \\
\hline I & N11 & Mt. Nishime (1) & 2009.02.16-17 & 2 & 29 & $7 * *$ & 24.14 \\
\hline II & Iy 1 & Mt. Iyu (8) & 2007.03.06-11 & 6 & 66 & 0 & 0.00 \\
\hline II & Iy 1 & Mt. Iyu (8) & 2007.12.24-29 & 6 & 44 & 0 & 0.00 \\
\hline II & $\mathrm{Ib} 1$ & Mt. Ibu (2) & $2008.02 .15-24$ & 10 & 923 & 0 & 0.00 \\
\hline III & Y1 & Mt. Yonaha (6) & 2007.03.15-20 & 6 & 66 & 0 & 0.00 \\
\hline Mean & & & & & & & 1.15 \\
\hline Total & & & & 74 & 2,096 & 24 & \\
\hline
\end{tabular}

* The numbers in parentheses indicate site positions in Fig. 1.

** Seven spiny rats captured at this site were released without measurement because they were in excess of the number permitted by the protection laws.

by Styrax japonica, Camellia japonica and Schefflera octophylla in the middle layer, by Pleioblastus linearis and Ardisia quinquegona in the lower layer, and by Alpinia intermedia, Cyathea podophylla and Blechnum orientale in the understory layer. Acorns from Castanopsis sieboldii and Lithocarpus edulis trees, a principal food source of spiny rats in winter, had already disappeared from the ground at the time of the investigation (May 29, 2009).

Area I contained many more areas of unlogged forest compared to Areas II and III; according to a previous report, no logging had ever occurred at capture sites N3, N4, N6, N7 or N8 in Area I (Table 3) (Watanabe 2008). However, Area I had suffered deforestation at site N9 about 30 years ago, and deforestation and burning, prior to the establishment of Pinus luchuensis plantations, had occurred at site N11 about 30 years ago.

\section{Body measurements of spiny rats captured in this study}

In this study, five spiny rats were captured on March 3 and 9 in 2008 and 19 animals were captured on February 16 and 17 in 2009 in the most successful sites of Area I (Table 4). External measurements were made, reproductive status was examined, and tails tips were collected for cytogenetic analysis from 17 of the 24 spiny rats. The remaining seven animals were returned to Area I in 2009 without any measurements or tissue collection because they were in excess of the permitted number. All of the other spiny rats were subsequently released at their respective capture sites except for individual No. 4 (Table 4), which was almost dead in the trap when found due to being bitten by a dwarf lance head snake Ovophis okinavensis that had entered the trap first.

The body weights of the nine females measured in this study ranged from 51.0 to $169.0 \mathrm{~g}$, and those of the eight males from 43.4 to $154.2 \mathrm{~g}$ (Table 4 ). The sample of females included two juveniles (11.8\% of total 17 spiny rats), two sub-adults (11.8\%) and five adults (29.4\%); the male group included two juveniles (11.8\%), two sub-adults (11.8\%) and four adults (23.5\%) (Table 4). The sex ratio (male/total) for the spiny rats in this study was $0.5,0.5,0.4$ and 0.5 for juvenile, sub-adult, adult and total individuals, respectively.

No significant inter-sex differences between adult females and adult males were found for the measured external characters, except for the Jackson distance and the ratio of the Jackson distance to HBL in the individuals collected in this study (Table 5). In adult spiny rats, the mean Jackson distance in males (mean $\pm S E$ : 27.0 $\mathrm{mm} \pm 1.91, n=4)$ was significantly larger than that of females $(16.5 \mathrm{~mm} \pm 1.95, n=4)(P=0.008, F=14.795)$ (Table 5). The mean ratio of the Jackson distance to 


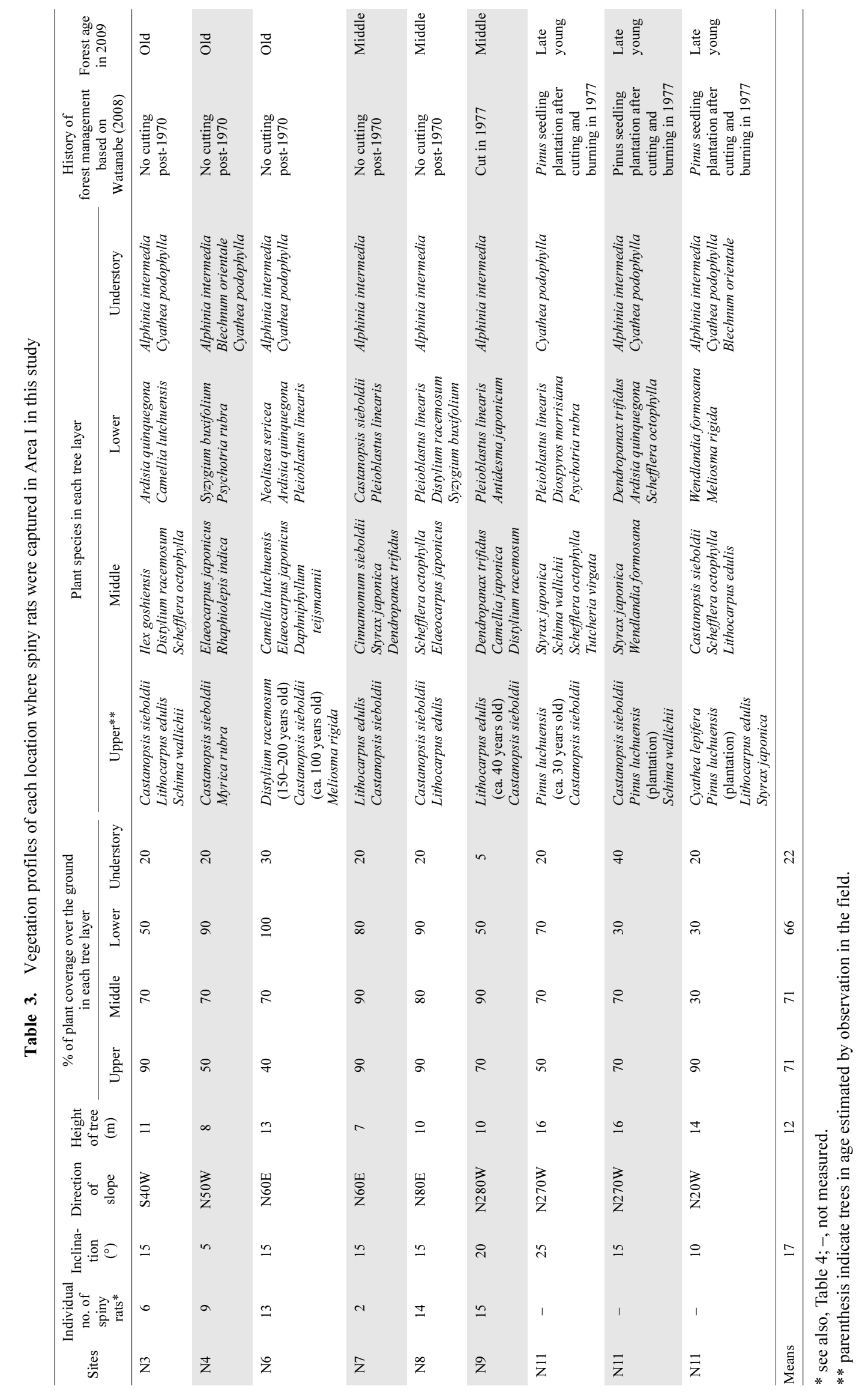




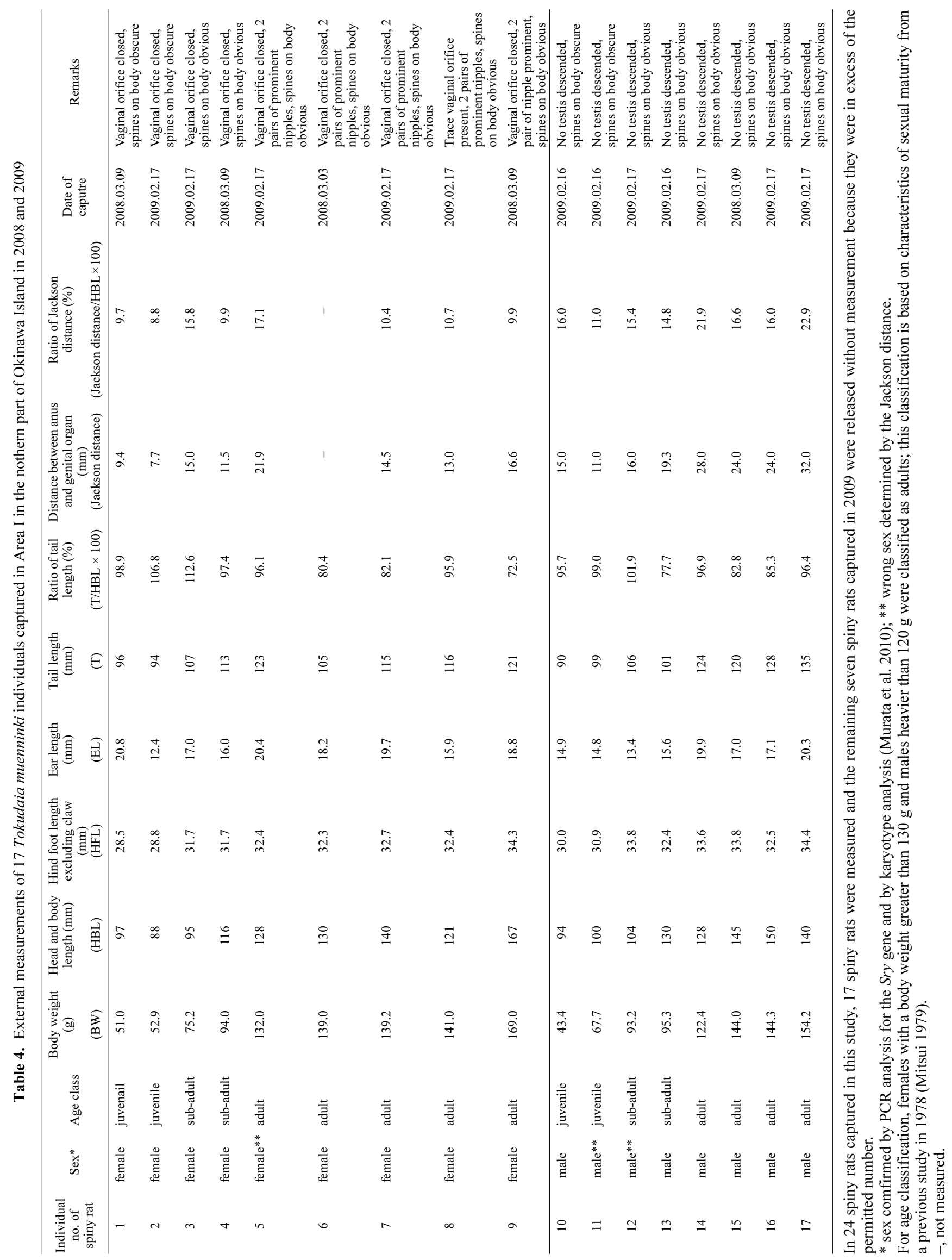




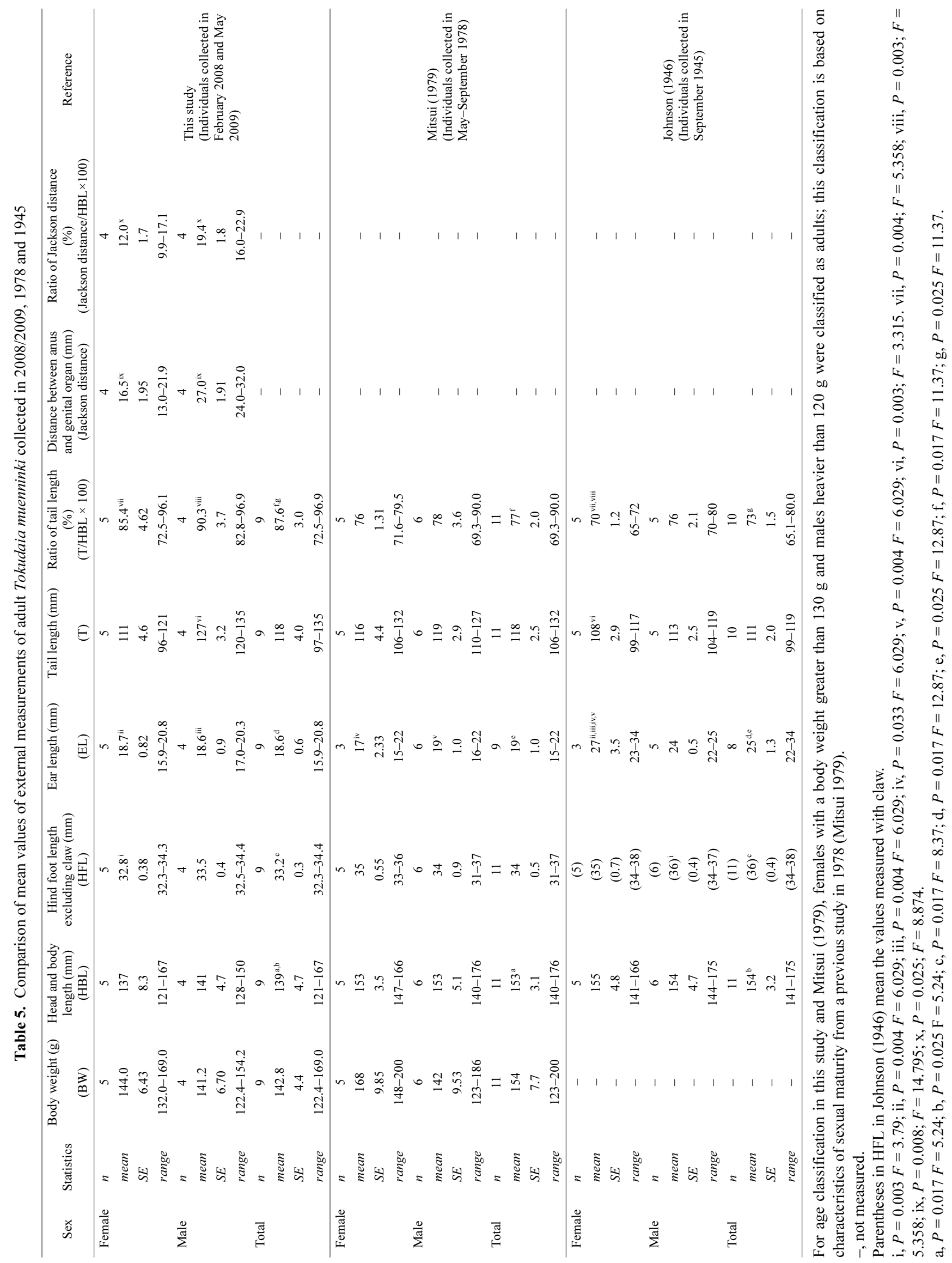


Table 6. Records of distribution of the spiny rat in Areas I, II and III in the northern part of Okinawa Island from 1945 to 2009

\begin{tabular}{|c|c|c|c|c|c|c|}
\hline $\begin{array}{c}\text { Year of } \\
\text { investigation }\end{array}$ & $\begin{array}{c}\text { Area of } \\
\text { investigation }\end{array}$ & $\begin{array}{l}\text { Areas inhabited } \\
\text { by spiny rats }\end{array}$ & $\begin{array}{c}\text { Method of } \\
\text { confirmation }\end{array}$ & $\begin{array}{c}\text { Number of fecal } \\
\text { samples that included } \\
\text { spines/number of } \\
\text { samples analyzed }\end{array}$ & $\begin{array}{l}\text { Frequency of spines } \\
\text { per sample }(\%)\end{array}$ & Reference \\
\hline $2008-2009$ & I, II, III & I & $\begin{array}{l}\text { Sensor camera and } \\
\text { trapping }\end{array}$ & - & - & This study \\
\hline $2001-2009$ & I, II, III & I & Mongoose trapping & - & - & $\begin{array}{l}\text { Ministry of the } \\
\text { Environment (2009) }\end{array}$ \\
\hline 2001 & II, III & II & Cat feces analysis & $1 / 28$ & 3.6 & Jogahara et al. (2003) \\
\hline 1999 & I, II & - & $\begin{array}{l}\text { Cat, dog and } \\
\text { mongoose feces } \\
\text { analysis }\end{array}$ & $0 / 22$ & 0.0 & $\begin{array}{l}\text { Kawauchi and Sasaki } \\
(2002)\end{array}$ \\
\hline 1997 & III & III & Cat feces analysis & $7 / 26$ & 12.5 & Ohshima et al. (1997) \\
\hline 1981 & III & III & Cat feces analysis & $16 / 20$ & 80.0 & $\begin{array}{l}\text { Okinawa Prefectural } \\
\text { Board of Education (1981) }\end{array}$ \\
\hline 1978 & I, III & III & Trapping & - & - & Mitsui (1979) \\
\hline 1975 & II, III & II, III & Cat feces analysis & $9 / 12$ & 75.0 & Miyagi (1976) \\
\hline 1945 & III & III & Trapping & - & - & Johnson (1946) \\
\hline
\end{tabular}

,- not analysed.

HBL in adult males $(19.4 \% \pm 1.8, n=4)$ was significantly larger than in adult females $(12.0 \% \pm 1.7, n=4)$ $(P=0.025, F=8.874)$ (Table 5$)$. In young spiny rats, the mean Jackson distances in males $(13.0 \mathrm{~mm}$ in juvenile and $17.7 \mathrm{~mm}$ in sub-adult) were larger than those in females $(8.5 \mathrm{~mm}$ in juvenile and $13.3 \mathrm{~mm}$ in sub-adult) with no significant differences (Table 4). The mean ratios of the Jackson distance to HBL in males (13.5\% in juvenile and $15.1 \%$ in sub-adult) were larger than those in females $(9.3 \%$ in juvenile and $12.9 \%$ in sub-adult) although the differences were not significant (Table 4). PCR based sex determination identified three individuals (17.6\% of the total of 17 individuals) that appeared to have been assigned to the wrong sex on the basis of their Jackson distances (see Table 4): animal No. 5 in adult (female by PCR, male by Jackson distance of $21.9 \mathrm{~mm}$ ), animal No. 11 in juvenile (male by PCR, female by Jackson distance of $11.0 \mathrm{~mm}$ ) and animal No. 12 in sub-adult (male by PCR, female by Jackson distance of $16.0 \mathrm{~mm}$ ).

With regard to reproductive condition, the vaginal orifice was closed and two pairs of nipples were prominent in the four adult females (Nos. 5, 6, 7 and 9) collected on March 3 and 9, 2008 and February 17, 2009 (Table 4). There was trace evidence of a vaginal orifice in a single adult female (No. 8) collected on February 17, 2009. None of the four adult males (Nos. 14, 15, 16 and 17) collected on March 9, 2008 and February 17, 2009 had descended testes. The juvenile females and males did not show clear body spines.

There were no significant inter-sex differences in the five external measurements (HBL, HFL, EL, T and T/ HBL) between adult females and adult males within each three groups collected in this study and in the past two studies in 1978 (Mitsui 1979) and 1945 (Johnson 1946), and there were no significant inter-sex differences in the body weight within each two groups collected in this study and in 1978 (Mitsui 1979) (Table 5). Therefore, we compared the body measurement of individuals including both sexes in each group. The mean HBL in total individuals including both sexes in this study (139 \pm $4.7 \mathrm{~mm}, n=9$ ) was significantly shorter than that in 1978 $(153 \pm 3.1 \mathrm{~mm}, n=11)(P=0.017, F=5.24)$ and that in $1945(154 \pm 3.2 \mathrm{~mm}, n=11)(P=0.025, F=5.24)$, but there were no significant differences in mean tail length among three groups (Table 5). Therefore, the mean ratio of tail length in this study $(87.6 \pm 3.0 \%, n=9)$ was significantly greater than that in $1978(77 \pm 2.0 \%, n=11)$ $(P=0.017, F=11.37)$ and that in $1945(73 \pm 1.5 \%, n=$ 10) $(P=0.025, F=11.37)$. The mean EL in $1945(25 \pm$ $1.3 \mathrm{~mm}, n=8)$ was significantly longer than that in 1978 $(19 \pm 1.0 \mathrm{~mm}, n=9)(P=0.025, F=12.87)$ and that in this study $(18.6 \pm 0.6 \mathrm{~mm}, n=9)(P=0.017, F=12.87)$. The mean HFL in this study $(33.2 \pm 0.3 \mathrm{~mm}, n=9)$ was significantly shorter than that in $1945(36 \pm 0.4 \mathrm{~mm}, n=$ 11) $(P=0.017, F=8.37)$ because the values of HFL by 
Johnson (1946) were measured including claw. There were eight significant differences in the mean values of the four external measurements (HFL, EL, T and T/ HBL) among each sex group in three collections (see Table 5). Although the mean body weights did not differ significantly between individuals collected in this study and in 1978 (Mitsui 1979) (Table 5), the heaviest individuals recorded in this study (169 $\mathrm{g}$ for female and $154 \mathrm{~g}$ for male) were lighter than those recorded in 1978 (200 $\mathrm{g}$ for female and $186 \mathrm{~g}$ for male).

\section{Discussion}

\section{Reduction in distribution of spiny rats and their rediscovery}

Our study provides the first evidence of the current range and distribution of the spiny rat on Okinawa Island. There have been few previous reports on the distribution of the spiny rat, and the available information is derived from two trapping investigations and from analyses of the feces of invasive predators, such as feral cats Felis silvestris catus, dogs Canis lupus familiaris and mongoose Herpestes auropunctatus (Table 6). We used $H$. auropunctatus here instead of $H$. javanicus as the scientific name of the mongoose based on the recent molecular phylogenetical studies (Veron et al. 2007; Gilchrist et al. 2009; Patou et al. 2009).

In regions to the south of the main location (Area I) identified in this study, there is some evidence of the occurrence of spiny rats in Areas II and III in the 7 to 11 years prior to our rediscovery of spiny rats in 2008 . Remnants of spiny hairs from spiny rats were identified in cat feces from Ohgimi Village on Mount Tamatsuji in 1997 (No. 10 in Fig. 1), which is thought to be the most southern habitat of the species (Ohshima et al. 1997). They were also identified in cat feces from Mount Yonaha in 1975-1997 (No. 6) (Miyagi 1976; Okinawa Prefectural Board of Education 1981; Ohshima et al. 1997), from the headwaters of the Aha River in 1997 (No. 5) (Ohshima et al. 1997) and from the Fun River in 2001 (No. 2) (Jogahara et al. 2003). The frequency of spiny rat remains in cat feces decreased from $75.0 \%$ in 1975 and $80.0 \%$ in 1981 to 3.6\% in 2001 in Areas II and III (Table 6). The available information indicates that the distribution of spiny rats has declined during 19752001.

There are no data on the hunting ranges of feral cats in northern Okinawa Island, thus, the distance between the place where a cat fed on a spiny rat and the place where it defecated is unknown. Studies on feral cats elsewhere indicate that they do not travel long distances between their sites of feeding and their defecation places in a single day, depending on food conditions and their home range (Fitzgerald and Turner 2000). Feral cats average $519 \mathrm{~m}$ per day (range 30-1,770 m) for hunting, and defecate one scat per day (Konecny 1987; Fitzgerald and Turner 2000). Therefore, it is likely that the information on spiny rat distribution obtained from analysis of feral cat feces provides a reasonably accurate indication of past distribution patterns.

The negative impact of predation by invasive mammals, as described above, may have accelerated extinction of the spiny rat in the northern part of Okinawa Island. In addition, loss of suitable habitats may also have affected spiny rat as logging occurred in Areas II and III between 1970 and 1990 (Watanabe 2008). In contrast, large-scale logging has not occurred in Area I (Table 3) (Watanabe 2008). Therefore, the negative impacts for spiny rats in Areas II and III may largely be a consequence of a combination of cat predation since the 1970s and habitat loss from logging. Subsequent to the study in 2001 (Jogahara et al. 2003), no evidence of spiny rat remains has been obtained from analyses of cat feces or those of other predators; this led to the suggestion that the spiny rat might be extinct on Okinawa Island.

Contrary to the suggestion of species extinction, our sensor camera and trapping analyses of Area I identified an extant of spiny rats. Although we also examined potential habitats for spiny rats in Areas II and III during 2007 and 2009, we obtained no evidence for their occurrence in these areas. We therefore suspect that the population in Area I might contain the only significant group of spiny rats in the northern part of Okinawa Island. In addition, the mongoose capture project in northern part of Okinawa Island (including Areas I, II and III) from 2001 to 2009 , with a total of more than $3,000,000$ trapdays, did not trap any spiny rats except a few spiny rats trapped in the same location as in the study in Area I (Table 6) (Ministry of the Environment 2009). Our rediscovery of spiny rats in the northern part of Okinawa Island and identification of their current main region of occurrence in this study comes after an interval of 30 years since the previous trapping study in 1978 (Mitsui 1979) and of seven years since survey evidence in 2001 (Jogahara et al. 2003).

The disappearance of spiny rats from the southern part of their previous distribution range area and the reduc- 
tion in their numbers on Okinawa Island is similar to that recorded for the Okinawa rail Gallirallus okinawae. In 2001, the southern limit of the Okinawa rail was about $10 \mathrm{~km}$ further north compared to 1986 and a central area of occurrence had also disappeared, probably due to the negative impacts of invasive predators, such as the mongoose and feral cat (Ozaki et al. 2002; Yamada et al. 2009).

\section{Characteristics of external measurements and reproduction}

There were no significant difference in external measurements between adult females and males in this study, except for the Jackson distance and the ratio of the Jackson distance to HBL. These latter characteristics, especially the Jackson distance, are useful for determining the sex of individuals during the non-breeding season, and also in juveniles and sub-adults. However, our PCR analysis suggested the possibility of a low rate of errors in distinguishing the sexes based only on the Jackson distance. The errors are likely to result from inter-individual variation or incorrect measurements, and it will be necessary to carry out further PCR analyses on a larger number of samples to determine the cause.

The mean HBL in this study $(139 \pm 4.7 \mathrm{~mm})$ was significantly shorter than the previous two groups collected in 1978 (Mitsui 1979) $(153 \pm 3.1 \mathrm{~mm})$ and 1945 (Johnson 1946) $(154 \pm 3.2 \mathrm{~mm})$. And the maximum body weights (169 $\mathrm{g}$ for females and $154 \mathrm{~g}$ for males) in this study were lower than those ( $200 \mathrm{~g}$ for females and $186 \mathrm{~g}$ for males) from animals collected during the nonbreeding season (May to September) in 1978 (Mitsui 1979), but there was no significant difference in the mean body weight between two groups (Table 5). Although our sample size is small, the apparent reduction in large-sized individuals in the present study is likely due to deterioration in food availability, reduction of habitat size, and reduction of population. Further studies are necessary to determine and monitor the vulnerability of the population.

With regard to reproduction, juvenile and sub-adult individuals were collected in this study from midFebruary to early March. The adult individuals collected here displayed no indications of reproductive activity. We conclude, therefore, that the period from midFebruary to early March is part of the non-breeding season and is the time when sub-adults and juveniles switch from being nursed to independence. The breeding season (parturition) is thought to be during October and November, with a litter size of 5-10 (Kaneko 2005).
Characterization of external aspects of the body morphology of the spiny rat is of value for distinguishing this species from the invasive black rat Rattus rattus, which lives allopatrically on Okinawa Island. The relative length of the tail to HBL (T/HBL \%) in the spiny rat was $87.6 \%$ for adults $(85.4 \%$ for females and $90.3 \%$ for males; Table 5) in the study, which is substantially lower than that of the black rat (109.3\%; Yoshida et al. 1971), Thus, in a field survey with an auto sensor camera, any individual observed with such characteristics as a relatively short and slender tail, a dark body color and a prominent forehead is likely to be a spiny rat.

\section{Conservation}

Measures for conservation of the main region in Area I where the spiny rats are located are urgently required. In particular, measures against the negative impact of habitat degradation due to logging and of invasive species, such as feral cats, mongooses and the black rat, should be implemented in this area and in peripheral surrounding areas in order to support survival of this small population of spiny rats. On Amami-Ohshima Island, although the population of Amami spiny rats was severely deleted by feral dog (Watari et al. 2007) and mongoose predation (Yamada and Sugimura 2004), the distribution of the Amami spiny rat has shown recent signs of recovery following measures against these predatory species (Ministry of the Environmental 2010).

It is possible that other small populations of spiny rats still exist in the northern part of Okinawa Island in addition to that identified in this study, particularly in forests dominated by the same tree species as Area I, namely Castanopsis sieboldii, Lithocarpus edulis, Distylium racemosum and Schima wallichii. Further study is necessary to elucidate the fundamental ecology of this species as an aid to its conservation; in particular, it will be essential to determine the distribution range, population size, and population genetics of the species, to identify negative factors that threaten survival, and to develop a captive breeding technique.

Monitoring of changes in distribution range and population size is important for conservation of endangered species. This study confirmed that a combination of monitoring via sensor cameras and trapping could be used to determine the presence and distribution of a species. However, we also suggest that it may be necessary to increase the numbers of individuals that can be captured; the current limit is based on the guidelines for use and collection of animals in research (Taxonomic Names 
and Collections Committee in the Mammalogical Society of Japan 2009). At present, the maximum number of individuals that can be captured is limited to 5-10 individuals per year by the Agency for Cultural Affairs and the Ministry of the Environment. This somewhat low limit hinders study of the species, and makes it difficult to conduct scientific research of relevance to its conservation.

In conclusion, our study has shown the survival of a small population of the spiny rat in the wild. Nevertheless, our results do not alter the situation of the spiny rat with regard to its vulnerability to extinction. Continuous investigation and monitoring will be necessary to ensure conservation of the species.

Acknowledgments: We thank Y. Miyake, S. Fukuchi, H. Shichiri, N. Murayama, N. Kudaka, Y. Toguchi, M. Kudaka, T. Harato, T. Komatsu, R. Fujii, A. Takahashi, Y. Yamamoto, K. Shionosaki, K. Ozaki, K. Ishida, and $\mathrm{S}$. Yasumura for their help in field research and information. We also thank M. Izawa for providing the valuable reference, and Y. Watari for his help. We also thank the assistance of anonymous referees and R. Masuda, the editor in chief for critically reading and help to improve the manuscript. This study was supported in part by the Project of Biodiversity Evaluation in Ryukyu Archipelago of the WWF-Japan during 2008-2009, and by the Naha Nature Conservation Office of the Ministry of the Environment.

\section{References}

Abe, Y. 1933. On the Amami oshima spiny rat. Botany and Zoology 1: 936-942 (in Japanese).

Arakawa, Y., Nishida-Umehara, C., Matsuda, Y., Sutou, S. and Suzuki, H. 2002. X-chromosomal localization of mammalian Ylinked genes in two $\mathrm{X} 0$ species of the Ryukyu spiny rat. Cytogenetic and Genome Research 99: 303-309.

Endo, H. and Tsuchiya, K. 2006. A new species of Ryukyu spiny rat, Tokudaia (Muridae: Rodentia), from Tokunoshima Island, Kagoshima Prefecture, Japan. Mammal Study 31: 47-57.

Endo, H., Hattori, S., Hayashi, Y. and Tsuchiya, K. 2008. Morphological comparisons between three species of the Ryukyu spiny rats. Mammal Study 33: 1-10.

Fitzgerald, M. and Turner, D. C. 2000. Hunting behaviour of domestic cats and their impact on prey populations. In (D. C. Turner and P. Bateson, eds.) The Domestic Cats: the Biology of Its Behaviour, 2nd ed., pp. 152-175. Cambridge University Press, Cambridge.

Gilchrist, J. S., Jennings, A. P., Veron, G. and Cavallini, P. 2009. Family Herpestidae. In (D. E. Wilson and R. A. Mittermeier, eds.) Handbook of the Mammals of the World, vol. 1, Carnivores, pp. 262-328. Lynx Edicions, Barcelona.

Hilton-Taylor, C. 2000. 2000 IUCN Red List of Threatened Species. IUCN, Gland, Switzerland and Cambridge, UK, Xviii +61 pp.
Iwasa, M. A. 2009. Tokudaia muenninki (Johnson, 1946). In (S. D. Ohdachi, Y. Ishibashi, M. A. Iwasa and T. Saitoh, eds.) The Wild Mammals of Japan, pp. 162-163. Shoukadoh Book Sellers, Kyoto.

Jogahara, T., Ogura, G., Sasaki, T., Takehara, K. and Kawashima, Y. 2003. Food habits of cats (Felis catus) in forests and villages and their impacts on native animals in the Yambaru area, northern part of Okinawa Island, Japan. Honyurui Kagaku (Mammalian Science) 43: 29-37 (in Japanese with English abstract).

Johnson, D. H. 1946. The spiny rat of the Riu Kiu island. Proceedings of the Biological Society of Washington 59: 169-172.

Kaneko, Y. 2001. Morphological discrimination of the Ryukyu spiny rat (genus Tokudaia) between the islands of Okinawa and Amami Oshima, in the Ryukyu Islands, southern Japan. Mammal Study 26: $17-33$.

Kaneko, Y. 2005. Muridae. In (H. Abe, ed.) A Guide to the Mammals of Japan, pp. 125-144. Tokai University Press, Hadano, Kanagawa (in Japanese with English abstract).

Kawauchi, N. and Sasaki, T. 2002. On the distribution and food habit of invasive predators (small Asian mongoose, feral dogs and cats) in forests in the northern part of Okinawa Island. Journal of the Biological Society of Okinawa 40: 41-50 (in Japanese).

Kobayashi, T., Yamada, F., Hashimoto, T., Abe, S., Matsuda, Y. and Kuroiwa, A. 2007. Exceptional minute sex-specific region in the X0 mammal, Ryukyu spiny rat. Chromosome Research 15: 175187.

Kobayashi, T., Yamada, F., Hashimoto, T., Abe, S., Matsuda, Y. and Kuroiwa, A. 2008. Centromere repositioning in the X chromosome of X0/X0 mammals, Ryukyu spiny rat. Chromosome Research 16: 587-593.

Konecny, M. J. 1987. Home range and activity patterns of feral house cats in the Galapagos Islands. Oikos 50: 17-23.

Kuroiwa, A., Ishiguchi, Y., Yamada, F., Abe, S. and Matsuda, Y. 2010. Loss of the Y chromosome. Chromosoma 119: 519-526.

Ministry of the Environment. 2002. Threatened Wildlife of Japan, Red Data Book 2nd ed. Volume 1, Mammalia. Japan Wildlife Research Center, Tokyo, 177 pp. (in Japanese).

Ministry of the Environment. 2009. Report of Java Mongoose Capturing Project in the Northern Okinawa Island (FY2008). Ministry of the Environment, Naha, 136 pp. (in Japanese with English summary).

Ministry of the Environment. 2010. Report of Java Mongoose Capturing Project in Amami-Ohshima Island (FY2009). Ministry of the Environment, Naha, 202 pp. (in Japanese).

Mitsui, K. 1979. On the Ecological Distribution, Growth, Behavior and Food Habit of Okinawa Spiny Rat (Tokudaia osimensis muenninki Johnson). Graduation Thesis of the University of the Ryukyus, unpublished, 62 pp. (in Japanese).

Miyagi, S. 1976. Preliminary report on feral cats and Okinawa spiny rats in the habitat of Okinawa woodpecker Sapheopipo noguchii. Series of Investigation on the Natural Monuments in Okinawa 5: 38-42 (in Japanese).

Murata, C., Yamada, F., Kawauchi, N., Matsuda, Y. and Kuroiwa, A. 2010. Multiple copies of SRY on the large Y chromosome of the Okinawa spiny rat, Tokudaia muenninki. Chromosome Research 18: 623-634.

Nakamura, T., Kuroiwa, A., Nishida-Umehara, C., Matsubara, K., Yamada, F. and Matsuda, Y. 2007. Comparative chromosome painting map between two Ryukyu spiny rat species, Tokudaia osimensis and Tokudaia tokunoshimensis (Muridae, Rodentia). Choromosome Research 15: 799-806.

Ohshima, N., Kinjo, M., Murayama, N., Obara, Y. and Higashimoto, H. 1997. Actual Conditions of Important Native Animals and 
Invasive Animals, and Impacts of Invasive Animals on Important Native Animals. Okinawa Branch of Japanese Bird Society, Okinawa, 86 pp. (in Japanese).

Okinawa Prefectural Board of Education. 1981. Report of investigation on actual condition of Ryukyu long-haired rat Diplothrix legatus. Series of Investigation on the Natural Monuments in Okinawa 22: 1-65 (in Japanese).

Ozaki, K., Baba, T., Komeda, S., Kinjo, M., Toguchi, Y. and Harato, T. 2002. The declining distribution of the Okinawa rail Gallirallus okinawae. Journal of Yamashina Institute for Ornithology 34: 136-144 (in Japanese with English abstract).

Ozawa, T. 2009. Origin and formative process of endemic fauna of the Ryukyu Archipelago, viewed from temporal changes of Pleistocene vertebrate fauna. Abstracts and Programs of the 158th Regular Meeting, Palaeontological Society of Japan: 5 (in Japanese).

Patou, M. L., Mclenachan, P. A., Morley, C. G., Couloux, A., Cruaud, C., Jennings, A. P. and Veron, G. 2009. Molecular phylogeny of the Herpestidae (Mammalia, Carnivora) with a special emphasis on the Asian Herpestes. Molecular Phylogenetics and Evolution 53: $69-80$

Sutou, S., Mitsui, Y. and Tsuchiya, K. 2001. Sex determination without the Y Chromosome in two Japanese rodents Tokudaia osimensis osimensis and Tokudaia osimensis spp. Mammalian Genome 12: 17-21.

Suzuki, H., Iwasa, M. A., Ishii, N., Nagaoka, H. and Tsuchiya, K. 1999. The genetic status of two insular populations of the endemic spiny rat Tokudaia osimensis (Rodentia, Muridae) of the Ryukyu Islands, Japan. Mammal Study 24: 43-50.

Suzuki, H., Tsuchiya, K. and Takezaki, N. 2000. A molecular phylogenetic framework for the Ryukyu endemic rodents Tokudaia osimensis and Diplothrix legata. Molecular Phylogenetics and Evolution 15: 15-24.

Taxonomic Names and Collections Committee in the Mammalogical Society of Japan. 2009. Guideline for use and collection of animals in research, 2009 revision. Honyurui Kagaku (Mammalian Science) 49: 303-319 (in Japanese).

Tsuchiya, K., Wakana, S., Suzuki, H., Hattori, S. and Hayashi, Y. 1989. Taxonomic study of Tokudaia (Rodentia: Muridae): I. Genetic differentiation. Memoirs of National Science Museum, Tokyo 22: 227-234 (in Japanese).

Yamada, F. and Sugimura, K. 2004. Negative impact of invasive small Indian mongoose Herpestes javanicus on native wildlife species and evaluation of its control project in Amami-Ohshima Island and Okiwana Island, Japan. Global Environmental Research 8: 117-124.

Yamada, F., Ogura, G. and Abe, S. 2009. Herpestes javanicus (É. Geoffroy Saint-Hilaire,1818). In (S. D. Ohdachi, Y. Ishibashi, M. A. Iwasa and T. Saitoh, eds.) The Wild Mammals of Japan, pp. 264-266. Shoukadoh Book Sellers, Kyoto.

Yoshida, T. H., Tsuchiya, K. and Moriwaki, K. 1971. Karyotypic differences of black rats, Rattus rattus, collected in various localities of east and Southeast Asia and Oceania. Chromosoma 33; 252-267.

Veron, G., Patou, M. L., Pothet, G., Simberloff, D. and Jennings, A. P. 2007. Systematic status and biogeography of the Javan and small Indian mongooses (Herpestidae, Carnivora). Zoologica Scripta 36: $1-10$

Watanabe, Y. 2008. Building of Environment GIS for Integrated Management. In (Okinawa Prefecture, ed.) Report of Integration of Coasts, Basins and Forests in Subtropical Islands, pp. 291-341. Okinawa Prefecture, Naha (in Japanese).

Watari, Y., Nagai, Y., Yamada, F., Sakoda, T., Kuraishi, T., Abe, S and Satomura, Y. 2007. The diet of dogs in the Amami-Oshima Island forest, with special attention to predation on endangered animals. Japanese Journal of Conservation Ecology 12: 28-35 (in Japanese with English abstract).

Received 11 January 2010. Accepted 18 August 2010 